\title{
Carbon Information Disclosure of Enterprises and their Value Creation Through Market Liquidity and Cost of Equity Capital
}

\author{
Li Li, Yuanhua Yang, Dengli Tang \\ Shenzhen Graduate School, Harbin Institute of Technology (China) \\ ximlli@126.com,260782245@qq.com,tangdengli_2008@163.com
}

Received: November 2014

Accepted: February 2015

\section{Abstract:}

Purpose: Drawing on asymmetric information and stakeholder theories, this paper investigates two mechanisms, namely market liquidity and cost of equity capital, by which the carbon information disclosure of enterprises can benefit their value creation.

Design/methodology/approach: In this research, web crawler technology is employed to study the link between carbon information disclosure and enterprises value creation, and the carbon information data are provided by all companies listed in Chinese A-share market

Findings: The results show that carbon information disclosure have significant positive influence on enterprise value creation, which is embodied in the relationship between carbon information disclosure quantity, depth and enterprise value creation, and market liquidity and cost of equity capital play partially mediating role in it, while the influence of carbon information disclosure quality and concentration on enterprise value creation are not significant in statistics.

Research limitations/implications: This paper explains the influence path and mechanism between carbon information disclosure and enterprise value creation deeply, answers the question of whether carbon information disclosure affects enterprise value creation or not in China. 
Practical implications: This paper finds that carbon information disclosure contributes positively to enterprise value creation suggests that managers can reap more financial benefits by disclosing more carbon information and investing carbon emissions management. So, managers in the enterprises should strengthen the management of carbon information disclosure behavior.

Originality/value: The paper gives a different perspective on the influence of carbon information disclosure on enterprise value creation, and suggests a new direction to understand carbon information disclosure behavior.

Keywords: carbon information disclosure, market liquidity, cost of equity capital, enterprises value creation

\section{Introduction}

With the coming of low carbon economy era, carbon information disclosure has become an important problem and is widely concerned by government and all level of society. Many environmental studies have analyzed the benefits carbon information disclosure brought to enterprise value creation (Chapple, Clarkson \& Gold, 2013; Griffin, Lont \& Sun, 2011; Nishitani \& Kokubu, 2012; Saka \& Oshika, 2014). However, these researches might have some limitations. Firstly, most existing research focused on the short-term economic consequences, such as stock price and market reflect. Hsu \& Wang (2013) discussed the influence of carbon information disclosure on shareholders' equity, while it is lack of research on its influence on long-term economic consequences. Secondly, the existing research about the influence of carbon information disclosure on market reaction focuses on the samples of western countries. Matsumura, Prakash and Vera-Muñoz (2013) and Hsu and Wang (2013) just focused on stock market in U.S. There are few researches which considered the market and situation in developing countries, especially Asian countries. Thirdly, the research conclusion is confused and inconsistent

The above research gap leads us to probe the following timely questions. Does carbon information disclosure bring a positive effect on enterprise value creation in China? What is the influence path and mechanism between the two? To address these research issues, we examine the paths through which carbon information disclosure enhances enterprise value creation via market liquidity and cost of equity capital. We develop and empirically test the theoretical paths grounded in asymmetric information and stakeholder theories, followed by statistical analysis of carbon information data collected by using web crawler technology from all companies listed in Chinese A-share market to validate the postulated relationships among carbon information disclosure, market liquidity, cost of equity capital and enterprise value 
creation. The findings advance the knowledge frontier of theoretical research and add new empirical evidences for international and domestic carbon information disclosure researches, and help government to make new and effective carbon information disclosure guidelines and policies.

\section{Previous Review and Hypothesis Development}

\subsection{Carbon Information Disclosure and Enterprise Value Creation}

Many researchers have proved that carbon information disclosure will affect the decisionmaking of investors, and then leaded to the change of market performance (Elias, 2011; Matsumura et al., 2013). However, there were also some scholars who pointed out that carbon information disclosure behavior would not bring obvious economic consequences, and the cost of carbon disclosure behavior enterprises responded to climate change was very expensive (Fisher-Vanden \& Thorburn, 2011). In addition, some researchers suggested that carbon information disclosure and firm value had correlation, but not significant (Shu, Ying \& Qian, 2013). The key reason is that existing studies have largely related carbon information disclosure to firm value directly, ignore the role of the intermediate variables such as market liquidity and do not explore the influence path and mechanism between carbon information disclosure and enterprise value creation.

We precisely examine these research issues in this study. Our framework proposes that the relationship between carbon information disclosure and enterprise value creation is better understood by the mediating link of market liquidity and cost of equity capital. We build on this literature to propose that carbon information disclosure is a driver of market liquidity and cost of equity capital and that the carbon information disclosure-enterprise value creation linkage exist(at least partially) because of the underlying process through market liquidity and cost of equity capital. Finally, we expect that the two factors mediates, at least partially, these moderated relationships.

\subsection{Carbon Information Disclosure and Market Liquidity}

Voluntary information disclosure is an efficient method in solving information asymmetry between companies and investors, and improving the level of liquidity in stock market (Verrecchia, 2001). The influence carbon information disclosure brings to stock market liquidity is through solving information asymmetry and adverse selection problem between companies and investors (Verrecchia, 2001). Subsequently, Matsumura et al. (2013) confirmed that carbon information affected short-term performance of stock price. Griffin et al. (2011) also revealed that there always would be great disturbances of trading volume and stock price the 
very or the next day when emission reduction information were reported. Based on the above literatures, we propose the hypothesis as follows.

Hypothesis 1: Carbon information disclosure has significantly positive influence on market liquidity.

\subsection{The Mediating Role of Market Liquidity}

The existing finance literature shows accumulating evidence for the influence of market liquidity on enterprise value creation. Saka and Oshika (2014) explored that the increasing level of market liquidity will keep more stable stock price and decrease the volatility of stock price. So, stock volatility is negatively related to firm value, relative stability stock prices is good for the enhancement of firm value. In addition, high level of market liquidity will bring more other benefits to enterprise value (Hsu \& Wang, 2013). In linking this evidence for the influence of market liquidity on enterprise value creation with the influence of carbon information disclosure on market liquidity, a mediating role of market liquidity in the carbon information disclosure-enterprise value creation linkage might logically be expected. So, we propose the hypothesis as follows.

Hypothesis 2: Firms that are viewed more favorably for carbon information disclosure has significantly positive influence on enterprise value creation, and the level of market liquidity at least partially mediates this influence of carbon information disclosure on enterprise value creation.

\subsection{Carbon Information Disclosure and Cost of Equity Capital}

Cost of equity capital refers to the cost enterprise undertook to obtain funds by floating stocks, which is the opportunity cost of existing invest capital for shareholders, is the minimum rate of return required by common shareholders (Shu et al. 2013). Carbon information disclosure will increase the total amount of information, reduce the extent of information asymmetry between investors and adverse selection problems, and reduce the information possessed by managers privately Lambert, Leuz and Verrecchia (2007). At the same time, it can improve investor's stock purchase intention, increase market liquidity and low the cost of capital. Based on the above literatures, we propose the hypothesis as follows.

Hypothesis 3: Carbon information disclosure has significantly negative influence on cost of equity capital. 


\subsection{The Mediating Role of Cost of Equity Capital}

The influence of cost of equity capital on enterprise value creation is obvious. From the definition we can see that enterprise financing cost and investment return are important source of value creation. Generally speaking, financing cost is the investment return shareholder's required, namely cost of equity capital. So, when financing cost is higher, enterprise investment returns will be affected, even lower returns, while financing cost is lower, enterprises have larger space to obtain a higher investment return, so the lower the financing cost is, the more beneficial enterprise value is. In linking this evidence for the influence of cost of equity capital on enterprise value creation with the influence of carbon information disclosure on cost of equity capital, which represents the meditational pathway through which carbon information disclosure behavior affect enterprise value creation. Based on the above literatures, we propose the hypothesis as follows:

Hypothesis 4: Firms that are viewed more favorably for carbon information disclosure has significantly positive influence on enterprise value creation, and cost of equity capital at least partially mediates this influence.

\section{Research Design}

\subsection{Sample Selection and Data Source}

In china, there is few enterprise participated CDP project and disclosed carbon information. Therefore, research data comes from the listed companies who disclosed carbon information through media and company's web site. Meanwhile, for the sake of data consistency, given the period of data selection, between 1st Jan.2012 and 31st Dec.2012, the enterprises listed after 2012 are removed. This study firstly uses web crawler technology and designs topic-focused web crawler to collect carbon information for enterprise disclosed to establish the research database (as shown in figure 1). To maintain the consistency of data, sample enterprises belonged to financial and insurance industry are eliminated, and data source for other variables were obtained from CSMAR database. 


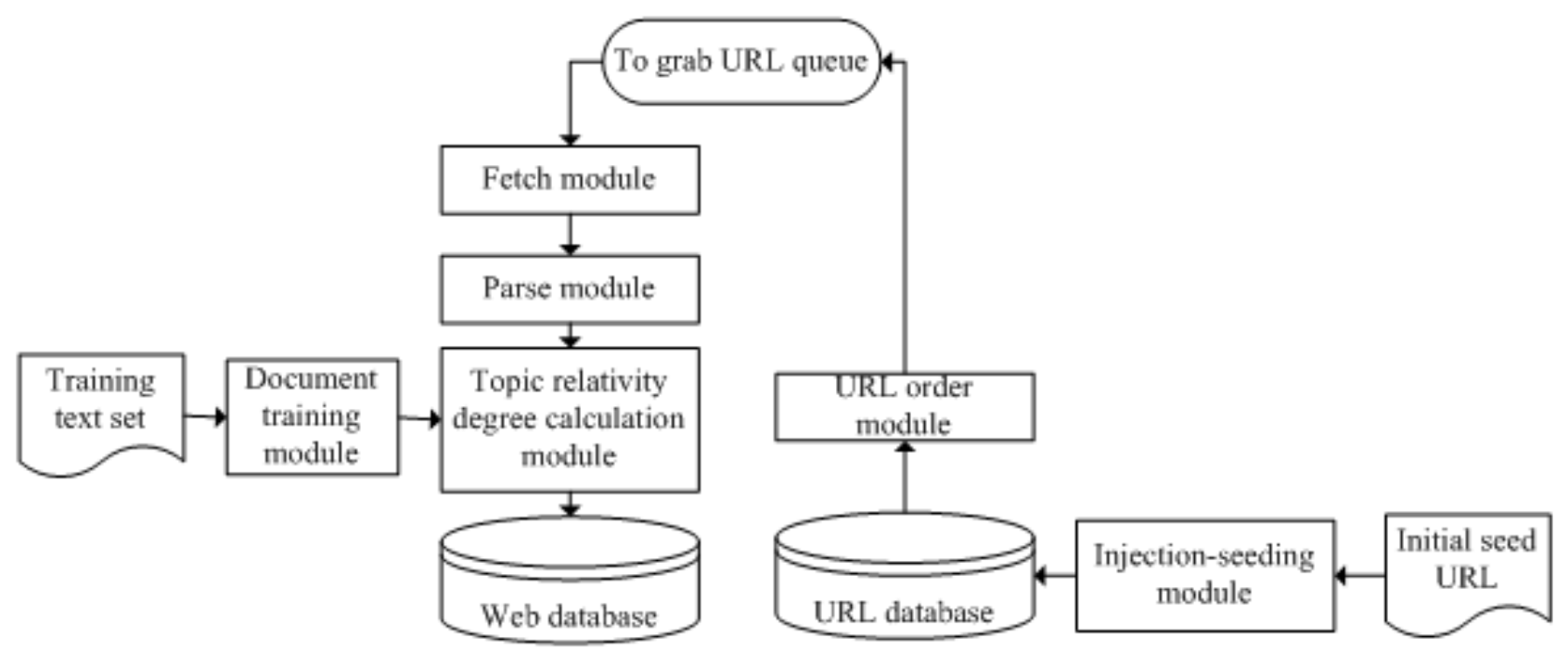

Figure 1. The structure of topic-focused web crawler

\subsection{Definition and Measurement of Variables}

\subsubsection{Measuring Carbon Information Disclosure}

(1) Quantity dimension-carbon information disclosure quantity (CDQ). Drawing lessons from Lambert, Leuz and Verrecchia (2013), this study calculated the total number of news articles to measure carbon information disclosure quantity. Accordingly, the carbon information disclosure quantity is equal to:

$$
C D Q=\sum_{i=1}^{n} W_{i}+\sum_{j=1}^{m} M_{j}+\sum_{y=1}^{s} F_{y}
$$

Where $W_{i}$ means article $i$ disclosed by one enterprise through the web site, $M_{j}$ means article $j$ disclosed by the enterprise through the media, and $F_{y}$ means article $y$ disclosed by the enterprise through other method besides annual reports.

(2) Quality dimension-carbon disclosure quality index (CDQI). According to the studies of Cormier, Ledoux and Magnan (2009), this study developed the index system to measure the quality of information disclosure. According to the definition of carbon information from CDP project, carbon information is divided into nine topics (CuiXiang, Yu, \& Haiou, 2012). Then, one article will belong to the topic if its number of keywords is the biggest. According to the current situation of China, we set topic 4 and 5 as general description and their articles with 1score; topic 1, 2, 3, 8 are set as specific description and their articles with 2 score, and the rest topics belongs to quantitative description and their articles get 3 score. 
Finally, the proportion of the sum of the scores the articles got on full marks of all articles is set as the measure carbon disclosure quality index. Accordingly, the carbon information disclosure quality is equal to:

$$
C D Q I=\frac{\left(\sum_{i=1}^{N} S_{1 i}+\sum_{j=1}^{M} S_{2 j}+\sum_{k=1}^{H} S_{3 k}\right)}{3(N+M+H)}
$$

Where $S_{1 i}$ means article $i$ of the total quantitative description, $N$ means the total amount of quantitative description. $S_{2 j}$ means article $j$ of the total specific description; $M$ means the total amount of specific description. $S_{3 k}$ means article $\mathrm{k}$ of the total general description; $\mathrm{H}$ means the total amount of general description.

(3) Depth dimension-carbon information disclosure depth index (CDDI). It is used to examine the difference distribution of carbon information between different stakeholders. Based on the results of Vurro and Perrini (2011), this research divided shareholders into stockholder, banker, customers, suppliers, government and community. The total number of information that one single enterprise disclosed is calculated for all its stakeholders. The proportion of the sum of information that one single enterprise disclosed for all its stakeholders on the total information the enterprise disclosed is set as the carbon disclosure depth index. Accordingly, the carbon information disclosure depth is equal to:

$$
C D D I=\sum_{j=1}^{m} s t k_{j i} \frac{\sum_{i=1}^{n} s t k_{j i}}{\sum_{j=1}^{m} \sum_{i}^{n} s t k_{j i}}
$$

Where: $s \mathrm{k}_{\mathrm{ji}}$ is the number of Chinese characters disclosed by Firm i for stakeholder $\mathrm{j}$, $\mathrm{m}$ means the number of stakeholders included the six stakeholders considered; $n$ means the number of sampled companies. The number of Chinese characters from each company for each stakeholder is weighted by the ratio of the total number of Chinese characters for that stakeholder on the total number of Chinese characters.

(4) Concentration dimension-carbon information disclosure concentration index (CDCI). Carbon disclosure concentration examines distribution situation of carbon information disclosure between different stakeholders. Drawing lessons from Vurro and Perrini (2011) we use the "Gini Coefficient" to measure it. Accordingly, the carbon information disclosure concentration is equal to:

$$
C D C I=\frac{1}{m}-\left(\frac{2}{m^{2} \bar{y}}\right)\left(y_{1}+2 y_{2}+\ldots m y_{m}\right)
$$


Where $\mathrm{y}_{1 . . .} \mathrm{y}_{\mathrm{m}}$ is a sequence of disclosure levels for the stakeholders; $\overline{\mathrm{y}}$ is the average disclosure level for each stakeholder in firm $\mathrm{i}$; $\mathrm{m}$ is the number of stakeholders.

In this study, we use turnover rate to measure market liquidity (Guoping \& Huilong, 2011). We use EP method to measure cost of equity capital, which is calculated by the reciprocal of price earnings ratio (Griffin et al., 2011). Drawing lessons from the research of Matsumura et al. (2013), we use market value to measure enterprise value creation. Based on the studies of Stanny (2013) this study chooses company size, debt levels, industry classification, enterprise growth ability and comprehensive level of risk as control variables. The explanations of variables in this model are shown in Table 1.

\begin{tabular}{|c|c|}
\hline Variables & Explanation of variables \\
\hline MV & Enterprise value creation, measured by stock market value \\
\hline CDQ & Carbon information disclosure quantity \\
\hline CDQI & Carbon information disclosure quality \\
\hline CDDI & Carbon information disclosure depth \\
\hline CDCI & Carbon information disclosure concentration \\
\hline SIZE & Company size, measured as the log of the firm's total assets at the end of the fiscal year \\
\hline INC & Industry classification, involves five industries \\
\hline LEV & Firm's leverage, measured as (dltt+dlc)/(ditt+dlc+ceq) \\
\hline GA & Company growth ability, measured as operating income growth rate \\
\hline TR & Market liquidity, measured by turnover rate \\
\hline EP & Cost of equity capital, measured by the reciprocal of priceearning ratio \\
\hline
\end{tabular}

Table 1. Explanation of variables in model

\subsection{The Construction of Multivariate Model}

After the related variables were determined, according to the four step method of mediating effect test from Baron and Kenny (1986), we build the following model to test the mediating effect of market liquidity and cost of equity capital. Model (1) is testing the influence of carbon information disclosure on enterprise value creation. Model (2) and (3) are testing the influence of carbon information disclosure on market liquidity and cost of equity capital, respectively. Model (4) and model (5) are used to test the influence of market liquidity and cost of equity capital on enterprise value creation, respectively. The mediating effect of market liquidity and cost of equity capital between carbon information disclosure and enterprise value creation as shown in model (6) and model (7), respectively.

$$
\mathrm{MV}=\alpha+\alpha_{1} \mathrm{CDQ}+\alpha_{2} \mathrm{CDQI}+\alpha_{3} \mathrm{CDDI}+\alpha_{4} \mathrm{CDCI}+\alpha_{5} \mathrm{SIZE}+\alpha_{6} \mathrm{LEV}+\alpha_{7} \mathrm{GA}+\alpha_{8} \mathrm{Beta}+\sum_{i=1}^{4} \alpha_{i+8} \mathrm{INC}+\varepsilon
$$




$$
\begin{gathered}
\mathrm{TR}=\beta+\beta_{1} \mathrm{CDQ}+\beta_{2} \mathrm{CDQI}+\beta_{3} \mathrm{CDDI}+\beta_{4} \mathrm{CDCI}+\beta_{5} \mathrm{SLZ}+\beta_{6} \mathrm{LEV}+\beta_{7} \mathrm{GA}+\beta_{8} \mathrm{BETA}+\sum_{i=1}^{4} \beta_{i+8}+\varepsilon \\
\mathrm{EP}=\gamma+\gamma_{1} \mathrm{CDQ}+\gamma_{2} \mathrm{CDQI}+\gamma_{3} \mathrm{CDDI}+\gamma_{4} \mathrm{CDCI}+\gamma_{5} \mathrm{SIZE}+\gamma_{6} \mathrm{LEV}+\gamma_{7} \mathrm{GA}+\gamma_{8} \mathrm{BETA}+\sum_{i=1}^{4} \gamma_{i+8} \mathrm{INC}+\varepsilon \\
\mathrm{MV}=\phi+\phi_{1} \mathrm{TR}+\phi_{2} \mathrm{SIZE}+\phi_{3} \mathrm{LEV}+\phi_{4} \mathrm{GA}+\phi_{5} \mathrm{BETA}+\sum_{i=1}^{4} \phi_{i+5} \mathrm{INC}+\varepsilon \\
\mathrm{MV}=\varpi+\varpi_{1} \mathrm{EP}+\varpi_{2} \mathrm{SIZE}+\varpi_{3} \mathrm{LEV}+\varpi_{4} \mathrm{GA}+\varpi_{5} \mathrm{BETA}+\sum_{i=1}^{4} \varpi_{i+5} \mathrm{INC}+\varepsilon \\
\mathrm{MV}=\theta+\theta_{1} \mathrm{CDQ}+\theta_{2} \mathrm{CDQI}+\theta_{3} \mathrm{CDDI}+\theta_{4} \mathrm{CDCI}+\theta_{5} \mathrm{TR}+\theta_{6} \mathrm{SIZE}+\theta_{7} \mathrm{LEV}+\theta_{8} \mathrm{GA}+\theta_{9} \mathrm{Beta}+\sum_{i=1}^{4} \theta_{i+9} \mathrm{INC}+\varepsilon \\
\mathrm{MV}=v+v_{1} \mathrm{CDQ}+v_{2} \mathrm{CDQI}+v_{3} \mathrm{CDDI}+v_{4} \mathrm{CDCI}+v_{5} \mathrm{EP}+v_{6} \mathrm{SIZE}+v_{7} \mathrm{LEV}+v_{8} \mathrm{GA}+v_{9} \mathrm{Beta}+\sum_{i=1}^{4} v_{i+9} \mathrm{INC}+\varepsilon
\end{gathered}
$$

\section{Analyses and Results}

\subsection{Descriptive Statistics of Samples}

The descriptive statistics of variables are shown in Table 2. As is shown in Table 2 the average level of carbon information disclosure quantity i s 20.7118 and 0.3726 , respectively; meanwhile, the average level of carbon information disclosure depth and concentration is 0.8556 and 0.2548 respectively. Therefore, the overall level of carbon information disclosure quality is not high.

\begin{tabular}{|c|c|c|c|c|c|}
\hline Variables & Observation & Average & Standard deviation & Minimum & Maximum \\
\hline CDQ & 1173 & 20.7118 & 34.7778 & 2.0000 & 302.0000 \\
\hline CDQI & 1173 & 0.3726 & 0.0726 & 0.3333 & 0.6667 \\
\hline CDDI & 1173 & 0.8556 & 0.1568 & 0.1016 & 1.0000 \\
\hline CDCI & 1173 & 0.2548 & 0.1766 & 0.0051 & 1.0000 \\
\hline SIZE & 1173 & 4.8161 & 0.2592 & 3.9480 & 5.8573 \\
\hline LEV & 1173 & 0.4643 & 0.2078 & 0.0260 & 0.9468 \\
\hline GA & 1173 & 0.5543 & 2.8159 & -0.8639 & 50.8180 \\
\hline BETA & 1173 & 0.9994 & 0.2081 & 0.2768 & 1.4879 \\
\hline TR & 1173 & 5.1572 & 6.0386 & 0.0662 & 57.7081 \\
\hline EP & 1173 & 0.0368 & 0.0257 & 0.0003 & 0.1462 \\
\hline MV & 1173 & 1.1309 & 2.0444 & 0.1000 & 19.6334 \\
\hline
\end{tabular}

Table 2. Basic descriptive statistics of variables 
What is more, the results of correlation analysis as shown in table 3. From Table 3 we could see that the relatively weak multi-colinearity between explanatory variables. Meanwhile, it can be found that carbon information disclosure quantity, depth and concentration were significant correlate to stock market value at the level of $5 \%$.

\begin{tabular}{|c|c|c|c|c|c|c|c|c|c|c|c|}
\hline Variables & CDQ & CDQI & CDDI & CDCI & SIZE & LEV & GA & BETA & TR & EP & MV \\
\hline CDQ & 1.000 & $0.298 * *$ & $-0.265^{* *}$ & $0.235^{-}$ & $0.441 * *$ & $0.163 * *$ & -0.013 & $\begin{array}{c}- \\
0.121 * *\end{array}$ & $-0.176 * *$ & $0.125 * *$ & $0.487 * *$ \\
\hline CDQI & $0.298 * *$ & 1.000 & $-0.101 * *$ & $0.137 * *$ & $0.058 *$ & $0.063 *$ & -0.027 & -0.032 & -0.040 & -0.027 & 0.027 \\
\hline CDDI & $-0.265^{* *}$ & $\overline{-} \overline{-} 101 * *$ & 1.000 & 0.013 & $-0.086 * *$ & -0.031 & 0.032 & -0.040 & -0.053 & 0.023 & $-0.097 * *$ \\
\hline CDCI & $-0.235 * *$ & $\begin{array}{c}- \\
0.137 * *\end{array}$ & 0.013 & 1.000 & $-0.097 * *$ & 0.014 & 0.028 & $0.087 * *$ & $0.065^{*}$ & $-0.089 * *$ & $-0.105^{* x}$ \\
\hline SIZE & $0.441 * *$ & $0.058 *$ & $-0.086 * *$ & $0 . \overline{-}$ & 1.000 & $0.494 * *$ & 0.007 & $\begin{array}{c}- \\
0.252^{*} *\end{array}$ & $-0.445 * *$ & $0.379 * *$ & $0.893 * *$ \\
\hline LEV & $0.163 * *$ & $0.063 *$ & -0.031 & 0.014 & $0.494 * *$ & 1.000 & $0.105^{* *}$ & -0.054 & $-0.231 * *$ & -0.010 & $0.317 * *$ \\
\hline GA & -0.013 & -0.027 & 0.032 & 0.028 & 0.007 & $0.105^{* *}$ & 1.000 & 0.000 & 0.014 & 0.007 & -0.005 \\
\hline BETA & $-0.121 * *$ & -0.032 & -0.040 & $0.087 * *$ & $-0.252 * *$ & -0.054 & 0.0003 & 1.000 & $0.543 * *$ & $-0.260 * *$ & $-0.305^{* *}$ \\
\hline $\mathrm{TR}$ & $-0.176 * *$ & -0.040 & -0.053 & $0.065 *$ & $-0.445^{* *}$ & $0.231 * *$ & 0.014 & $0.543 * *$ & 1.000 & $-0.200 * *$ & $-0.391 * *$ \\
\hline EP & $0.125 * *$ & -0.027 & 0.023 & $\begin{array}{c}- \\
0.089 * *\end{array}$ & $0.379 * *$ & -0.010 & 0.007 & $\begin{array}{c}- \\
0.260 * *\end{array}$ & $-0.200 * *$ & 1.000 & $0.324 * *$ \\
\hline MV & $0.487 * *$ & 0.027 & $-0.097 * *$ & $\begin{array}{c}- \\
0.105^{* *}\end{array}$ & $0.893 * *$ & $0.317 * *$ & -0.005 & $\stackrel{-}{-} \cdot 305^{* *}$ & $-0.391 * *$ & $0.324 * *$ & 1.000 \\
\hline
\end{tabular}

Note: $* *$ represents the significant correlation at level $1 \%$; means significant correlation at level $5 \%$.

Table 3. Correlation analysis on variables

\subsection{Regression Analysis}

\subsubsection{Results for the Mediating Role of Market Liquidity}

To establish the existence of this mediation effect, four conditions should hold (Baron \& Kenny, 1986): (1) The predictor variable (carbon information disclosure) should significantly influence the mediator variable (market liquidity); (2) the mediator should significantly influence the dependent variable (enterprise value creation); (3) the predictor (carbon information disclosure) variable should significantly influence the dependent variable (enterprise value creation); and (4) after we control for the mediator variable (market liquidity), the impact of the predictor (carbon information disclosure) on the dependent variable (enterprise value creation) should no longer be significant (for full mediation) or should be reduced in strength (for partial mediation). As table 4 shows, model 2 and model 4 meet the first two conditions. That is carbon information disclosure affects market liquidity, which is proved by the relationship between carbon information disclosure quantity, depth, concentration and 
enterprise value creation. Furthermore, market liquidity affects market value, which is consistent with existing studies Elias, 2011; Griffin et al., 2011).

Model 1 qualifies the third condition, the predictor variable of carbon information disclosure affects enterprise value creation in terms of market value, which is shown by the relationship between carbon information disclosure quantity, concentration and enterprise value creation. As table 4 shows, compared the correlation coefficient of model 1 and model 6 , the coefficient of carbon information disclosure quantity decreased from 0.0066 to 0.0059 , with the same significance level of $1 \%, \mathrm{t}$ value is 8.66 , which instructs that market liquidity plays partial mediation role in the relationship between carbon information disclosure quantity and enterprise value creation. The significance level of carbon information disclosure depth decreased from $1 \%$ to $5 \%$, which means market liquidity plays partial mediation role in the relationship between carbon information disclosure depth and enterprise value creation. The correlation coefficients of carbon information disclosure quality and concentration are not significant. As such, the data provide partly support for $\mathrm{H} 2$.

\begin{tabular}{|c|c|c|c|c|}
\hline Variables & $\begin{array}{c}\text { Model 1 } \\
\text { Coefficient }\end{array}$ & $\begin{array}{c}\text { Model 2 } \\
\text { Coefficient }\end{array}$ & $\begin{array}{c}\text { Model 4 } \\
\text { Coefficient }\end{array}$ & $\begin{array}{c}\text { Model 6 } \\
\text { Coefficient }\end{array}$ \\
\hline Constant & $-9.3973 * * *$ & $9.1531 * * *$ & $-6.7424 * * *$ & $-9.2792 * * *$ \\
\hline CDQ & $0.0066 * * *$ & $0.0005 *$ & & $0.0059 * * *$ \\
\hline CDQI & 0.1088 & -0.9153 & & 0.0944 \\
\hline CDDI & $0.1703 * * *$ & $1.0586 *$ & & $0.1842 * *$ \\
\hline CDCI & 0.0275 & $-1.1438 * *$ & & 0.0058 \\
\hline TR & & & $0.0013^{1}$ & $0.0026 * *$ \\
\hline SIZE & $2.1275 * * *$ & $-1.6093 * *$ & $1.6159 * *$ & $2.1110 * *$ \\
\hline LEV & $-0.3393 * * *$ & -0.3981 & $-0.1685 * * *$ & $-0.3125 * *$ \\
\hline GA & 0.0037 & -0.0090 & 0.0034 & 0.0067 \\
\hline BETA & $-0.2331 * * *$ & $3.6049 * * *$ & $-0.2875 * *$ & $-0.2893 *$ \\
\hline INC & control & control & control & control \\
\hline Adjusted R & $52.21 \%$ & $28.02 \%$ & $42.45 \%$ & $52.05 \%$ \\
\hline F-statistic & 107.7136 & 39.0217 & 97.0557 & 98.8739 \\
\hline Prob & 0.0000 & 0.0000 & 0.0000 & 0.0000 \\
\hline
\end{tabular}

Note: $* * *$ represents the significant correlation at level $1 \% ; * *$ means significant correlation at level $5 \%$; means significant correlation at level $10 \%$.

${ }^{1}$ Market liquidity positively related to enterprise value creation at level $20 \%$

Table 4 . Results of the mediating role of market liquidity 


\subsubsection{Results for the Mediating Role of Cost of Equity Capital}

Table 5 reports the results of the mediating role of cost of equity capital. As table 5 shows Model 3 meets the first condition. It suggests that carbon information disclosure quantity and depth are negative related to cost of equity capital, carbon information disclosure concentration is positive related to cost of equity capital, and the relationship between carbon information disclosure quality and cost of equity capital is not significant, which partly offered empirical support for $\mathrm{H} 3$, carbon information disclosure brings significant influence to cost of equity capital in capital market. Model 5 meets the second condition. That is cost of equity capital affects enterprise value creation. The results above mentioned are consistent with existing studies (Lambert et al., 2007; Shu et al., 2013). Model 1 qualifies the third condition, carbon information disclosure affects enterprise value creation in terms of market value, which is shown by the relationship between carbon information disclosure quantity, concentration and enterprise value creation.

As table 5 shows, compared the correlation coefficient of model 1 and 7 , the coefficient of carbon information disclosure quantity decreased from 0.0066 to 0.0065 , with the same significance level of $1 \%, \mathrm{t}$ value is 2.2 , which instructs that cost of equity capital plays partial mediation role in the relationship between carbon information disclosure quantity and enterprise value creation. The significance level of carbon information disclosure depth decreased from $1 \%$ to $5 \%$, which means cost of equity capital plays partial mediation role in the relationship between carbon information disclosure depth and enterprise value creation. The correlation coefficients of carbon information disclosure quality and concentration are not significant. As such, the data provide partly support for $\mathrm{H} 4$.

In addition, we carried out heteroscedasticity test and revised models to ensure the effectiveness of the estimation in the process of regression analysis. Then, this paper use Tuobin ' $Q$ as the substitution variable of enterprise value creation to check the results again. The results show that the fit of all model decreased a little than before, but generally support the empirical results we got before. 


\begin{tabular}{|c|c|c|c|c|}
\hline Variables & $\begin{array}{c}\text { Model 1 } \\
\text { Coefficient }\end{array}$ & $\begin{array}{c}\text { Model 3 } \\
\text { Coefficient }\end{array}$ & $\begin{array}{c}\text { Model 5 } \\
\text { Coefficient }\end{array}$ & $\begin{array}{c}\text { Model 7 } \\
\text { Coefficient }\end{array}$ \\
\hline Constant & $-9.3973 * * *$ & $-0.1698 * * *$ & $-7.0970 * * *$ & $-9.1386 * * *$ \\
\hline CDQ & $0.0066 * * *$ & $-0.000017 *$ & & $0.0065 * * *$ \\
\hline CDQI & 0.1088 & -0.0051 & & 0.0770 \\
\hline CDDI & $0.1703 * * *$ & $-0.0057 *$ & & $0.1768 * *$ \\
\hline CDCI & 0.0275 & $0.0079 * *$ & & 0.0406 \\
\hline EP & & & $-2.0844 * * *$ & $-2.0921 * *$ \\
\hline SIZE & $2.1275 * * *$ & $0.0478 * * *$ & $1.7157 * *$ & $2.0945 * * *$ \\
\hline LEV & $-0.3393 * * *$ & $-0.0230 * *$ & $-0.2118 * * *$ & $-0.3323 *$ \\
\hline GA & 0.0037 & $0.0005 *$ & 0.0033 & -0.0002 \\
\hline BETA & $-0.2331 * * *$ & $-0.0117 * *$ & $-0.3092 *$ & $-0.2624 * * *$ \\
\hline INC & control & control & control & control \\
\hline Adjusted R2 & $52.21 \%$ & $29.40 \%$ & $42.25 \%$ & $50.75 \%$ \\
\hline F-statistic & 107.7136 & 41.6790 & 96.2860 & 93.9150 \\
\hline Prob & 0.0000 & 0.0000 & 0.0000 & 0.0000 \\
\hline
\end{tabular}

Note: $* * *$ represents the significant correlation at level $1 \%$; ** means significant correlation at level $5 \%$; means significant correlation at level $10 \%$.

Table 5. Results of the mediating role of cost of equity capital

\section{Conclusions and Limitations}

How is carbon information disclosure related to enterprise value creation, and what is the influence path and mechanism between the two? Our study suggests the answer to these questions is that carbon information disclosure affects enterprise value creation partially through the mediator of market liquidity and cost of equity capital. By analyzing carbon information data in China, we find support for the hypothesized relationships that carbon information disclosure fosters market liquidity, which favorably contributes to value creation. On the other hand, carbon information disclosure benefits to low the cost of equity capital, which in turn improves the value creation of enterprises. This is consistent with the theorization of asymmetric information and stakeholder that information asymmetry problem is widespread in capital market.

Our study is a timely response to the call to broaden knowledge on carbon information disclosure influence enterprise value creation or not in China. In terms of Chinese reality, enterprises display low willingness to engage in CDP and to disclose carbon information. The key reason is that enterprises are not sure carbon information disclosure will bring benefits to them or not. The findings help enterprises to understand this question deeply.

Our finding that carbon information disclosure contributes positively to enterprise value creation suggests that managers can reap more financial benefits by disclosing more carbon information and investing carbon emissions management. So, managers should strengthen the 
management of carbon information disclosure behavior, especially the management of disclosure construction. It is found that disclosure quantity and disclosure depth has significant positive influence on corporate values, while excessive concentration information disclosure is unfavorable for the enterprises. Therefore, the management of carbon information disclosure is necessary.

There are two major limitations in this study. One is the computer program used in data processing was written by researchers themselves. The programming might be subjectivity. The other is that data collection and analysis process was highly labor intensive. Limited by our knowledge we chose an easy accessibility to measure carbon disclosure level, which might lead to the complexity of text data processing is not high and the scientific of the indicators need to be further improve.

\section{Acknowledgement}

Research works in this paper are financially supported by Research Planning Foundation in Humanities and Social Sciences of the Ministry of Education of China (Grant No. 13YJAZH044).

\section{References}

Baron, R.M., \& Kenny, D.A. (1986). The moderator-mediator variable distinction in social psychological research: conceptual, strategic, and statistical considerations. Journal of Personality and Social Psychology, 51(6), 1173. http://dx.doi.org/10.1037/0022-3514.51.6.1173

Chapple, L., Clarkson, P.M., \& Gold, D.L. (2013). The cost of carbon: Capital market effects of the proposed emission trading scheme (ETS). Abacus, 49(1), 1-33.

http://dx.doi.org/10.1111/abac.12006

Cormier, D., Ledoux, M., \& Magnan, M. (2009). The use of Web sites as a disclosure platform for corporate performance. International Journal of Accounting Information Systems, 10(1), 1-24. http://dx.doi.org/10.1016/j.accinf.2008.04.002

CuiXiang, T., Yu, L., \& Haiou, L. (2012). Discussion carbon disclosure status and improving of enterprise in China. Business Accounting, 10, 15-17.

Elias, M.B. (2011). The influence of corporate carbon disclosure on investor decisions and attitudes in South Africa.

Fisher-Vanden, K., \& Thorburn, K.S. (2011). Voluntary corporate environmental initiatives and shareholder wealth. Journal of Environmental Economics and Management, 62(3), 430-445. http://dx.doi.org/10.1016/j.jeem.2011.04.003

Griffin, P.A., Lont, D.H., \& Sun, Y. (2011). The relevance to investors of greenhouse gas emission disclosures. UC Davis Graduate School of Management Research Paper, 01-11. 
Guoping, T., \& Huilong, L. (2011). Environmental information disclosure, investor confidence and company value. Journal of Zhongnan University of Economics and Law, 06, 70-77.

Hsu, A.W., \& Wang, T. (2013). Does the market value corporate response to climate change? Omega, 41(2), 195-206. http://dx.doi.org/10.1016/j.omega.2011.07.009

Lambert, R., Leuz, C., \& Verrecchia, R.E. (2007). Accounting information, disclosure, and the cost of capital. Journal of Accounting Research, 45(2), 385-420. http://dx.doi.org/10.1111/j.1475679x.2007.00238.x

Lee, S.Y., Park, Y.S., \& Klassen, R.D. (2013). Market responses to firms' voluntary climate change information disclosure and carbon communication. Corporate Social Responsibility and Environmental Management.

Matsumura, E.M., Prakash, R., \& Vera-Muñoz, S.C. (2013). Firm-value effects of carbon emissions and carbon disclosures. The Accounting Review, 89(2), 695-724.

http://dx.doi.org/10.2308/accr-50629

Nishitani, K., \& Kokubu, K. (2012). Why does the reduction of greenhouse gas emissions enhance firm value? The case of Japanese manufacturing firms. Business Strategy and the Environment, 21(8), 517-529. http://dx.doi.org/10.1002/bse.734

Saka, C., \& Oshika, T. (2014). Disclosure effects, carbon emissions and corporate value. Sustainability Accounting, Management and Policy Journal, 5(1), 22-45.

http://dx.doi.org/10.1108/SAMPJ-09-2012-0030

Shu, L., Ying, Z., \& Qian, T. (2013). Can corporate social responsibility report reduce cost of equity capital? Accounting Research, 09, 64-70.

Stanny, E. (2013). Voluntary disclosures of emissions by US firms. Business Strategy and the Environment, 22(3), 145-158. http://dx.doi.org/10.1002/bse.1732

Verrecchia, R.E. (2001). Essays on disclosure. Journal of Accounting and Economics, 32(1): 97-180. http://dx.doi.org/10.1016/S0165-4101(01)00025-8

Vurro, C., \& Perrini, F. (2011). Making the most of corporate social responsibility reporting:

Disclosure structure and its impact on performance. Corporate Governance, 11(4), 459-474. http://dx.doi.org/10.1108/14720701111159280

Journal of Industrial Engineering and Management, 2015 (www.jiem.org)

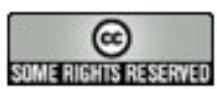

Article's contents are provided on a Attribution-Non Commercial 3.0 Creative commons license. Readers are allowed to copy, distribute and communicate article's contents, provided the author's and Journal of Industrial Engineering and Management's names are included. It must not be used for commercial purposes. To see the complete license contents, please visit http://creativecommons.org/licenses/by-nc/3.0/. 